\title{
Lactobacilli spp.: real-time evaluation of biofilm growth
}

Stacy Martinez ${ }^{1}$, Jonathan Gomez Garcia ${ }^{1,2}$, Roy Williams ${ }^{1,2}$, Moamen Elmassry ${ }^{3}$, Andrew West ${ }^{1}$, Abdul Hamood ${ }^{4}$, Deborah Hurtado ${ }^{5}$, Brent Gudenkauf ${ }^{1}$, Gary Ventolini ${ }^{1 *}$ and Natalia Schlabritz-Loutsevitch ${ }^{1,6^{*}}$

\begin{abstract}
Background: Biofilm is a fundamental bacterial survival mode which proceeds through three main generalized phases: adhesion, maturation, and dispersion. Lactobacilli spp. (LB) are critical components of gut and reproductive health and are widely used probiotics. Evaluation of time-dependent mechanisms of biofilm formation is important for understanding of host-microbial interaction and development of therapeutic interventions. Time-dependent $L B$ biofilm growth was studied in two systems: large biofilm output in continuous flow system (microfermenter (M), Institute Pasteur, France) and electrical impedance-based real time label-free cell analyzer (C) (xCELLigence, ACEA Bioscience Inc., San Diego, CA). L. plantarum biofilm growth in M system was video-recorded, followed by analyses using IMARIS software (Bitplane, Oxford Instrument Company, Concord, MA, USA). Additionally, whole genome expression and analyses of attached (A) and dispersed (D) biofilm phases at 24 and $48 \mathrm{~h}$ were performed.
\end{abstract}

Results: The dynamic of biofilm growth of L. plantarum was similar in both systems except for $D$ phases. Comparison of the transcriptome of A and D phases revealed, that 121 transcripts differ between two phases at 24 h. and 35 transcripts - at $48 \mathrm{~h}$. of $\mathrm{M}$ growth. The main pathways, down-regulated in A compared to D phases after $24 \mathrm{~h}$. were transcriptional regulation, purine nucleotide biosynthesis, and L-aspartate biosynthesis, and the upregulated pathways were fatty acid and phospholipid metabolism as well as $A B C$ transporters and purine nucleotide biosynthesis. Four $L B$ species differed in the duration and amplitude of attachment phases, while growth phases were similar.

Conclusion: $\angle B$ spp. biofilm growth and propagation area dynamic, time-dependent processes with species-specific and time specific characteristics. The dynamic of $L B$ biofilm growth agrees with published pathophysiological data and points out that real time evaluation is an important tool in understanding growth of microbial communities.

Keywords: Real-time detection, Biofilm, Lactobacilli, Micro-fermenter, xCELLigence, RNA-seq

\section{Background}

Recent development of the concept of the microbiome has opened the question of co-existence of bacterial communities and mammalian cells [1] as well the presence of bacterial communities as an essential component for host function and survival $[2,3]$. In the body, biofilm

\footnotetext{
* Correspondence: Gary.ventolini@ttuhsc.edu; Natalia.SchlabritzLutsevich@ttuhsc.edu

${ }^{1}$ Texas Tech University Health Sciences Center at the Permian Basin, 701 W. 5th Street, Odessa, TX 79763, USA

Full list of author information is available at the end of the article
}

formation represents a major mode of bacterial colonization that can spread out over $300-400 \mathrm{~m}^{2}$ of the surface areas in humans $[4,5]$. Growth of bacterial biofilms is a complex process involving three main phases: adhesion, biofilm maturation, and dispersion [1]. Adhesion starts with reversible and non-reversible attachment. The reversible process involves initial attachment and is driven by morphological, mechanical and electrical interactions with host cells $[1,6]$. For the adhesion process, bacteria express multiple type of adhesions, e.g. cell appendages, or pili, which facilitate bacterial binding

(c) The Author(s). 2020 Open Access This article is licensed under a Creative Commons Attribution 4.0 International License, which permits use, sharing, adaptation, distribution and reproduction in any medium or format, as long as you give appropriate credit to the original author(s) and the source, provide a link to the Creative Commons licence, and indicate if changes were made. The images or other third party material in this article are included in the article's Creative Commons licence, unless indicated otherwise in a credit line to the material. If material is not included in the article's Creative Commons licence and your intended use is not permitted by statutory regulation or exceeds the permitted use, you will need to obtain permission directly from the copyright holder. To view a copy of this licence, visit http://creativecommons.org/licenses/by/4.0/ The Creative Commons Public Domain Dedication waiver (http://creativecommons.org/publicdomain/zero/1.0/) applies to the data made available in this article, unless otherwise stated in a credit line to the data. 
to host glycoproteins [7] and oligosaccharides [8]. The maturation phase is characterized by cellular division, production of the extracellular matrix, and dispersion [9]. The time-line of biofilm development by different bacteria is an important parameter [10]. Lactobacilli species (spp.) $(L B)$ are abundant in human oral cavities [11], gut [12$14]$, vagina $[15,16]$ and milk [17]. $L B$ have been shown to display therapeutic properties, e.g. in prevention of adhesion of Trichomonas vaginalis (by L. gasseri) [18], Vibrio spp., [19] and interfering with immune cells [20]. Thus, understanding any of the dynamics of biofilm growth by $L B$ has high translational relevance. Despite the fact that $L B$ biofilm has been described extensively [21-25], the temporal dynamic of biofilm growth of these species has yet to be evaluated. Here, the temporal dynamic of $L B$ biofilm growth is described using two methods of label-free quantification: analyses of video-recording and electrical impedance-based technologies, as well as an additional RNA -sequencing was performed.

\section{Results}

\section{Large scale biofilm growth}

The total final weight of the biofilm was $0.51 \pm 0.09 \mathrm{~g}$ after $24 \mathrm{~h}$. $(n=6)$ and $3.41 \pm 0.26 \mathrm{~g}$ for $48 \mathrm{~h} .(n=6)$. The weight of the attached phase was $0.46 \pm 0.04 \mathrm{~g}(n=5)$, and the weight of the detached phase was $3.13 \pm 0.34 \mathrm{~g}(n=5)$ at $48 \mathrm{~h}$. Analyses of the video recording demonstrated growth of the attached phase, starting at $9 \mathrm{~h}$. post- inoculation (Fig. 1a and b), followed by continuous growth, reaching a detachment/plateau at $42 \mathrm{~h}$. The detached portion of the biofilm started to grow at $15 \mathrm{~h}$. (Figs. 1c and $2 \mathrm{~d}$ ) and continued to grow, not reaching a plateau at $48 \mathrm{~h}$. of recording. At approximately three-and-a-half hours, when formation of the biofilm had initiated, the software started to measure the biofilm and intensity, and the readout was corrected. At approximately $16 \mathrm{~h}$. a large detachment was noted and reflected in fluctuations in intensity. New growth and development on the spatula were reflected on the rebound of the intensity at approximately 17. $5 \mathrm{~h}$. (Supplementary material Video-recording S).

The best model for fit the intensity function was obtained with a cubic polynomial ( $\mathrm{R} 2$ between 0.971 to 0.992) equation. The increase of intensity was clearly contrasted between the attached and detached conditions. The predicted model showed a slight difference between intercepts since basal measurement. However, after intercepts adjustment, the delayed signal intensity from detached condition remained during the whole experiment (Fig. 2).

\section{Total genome expression of sedimentary and detached} phases of $L$. plantarum in large scale biofilm growth Comparison of attached and detached phases of biofilm growth revealed, that 121 transcripts differ between the

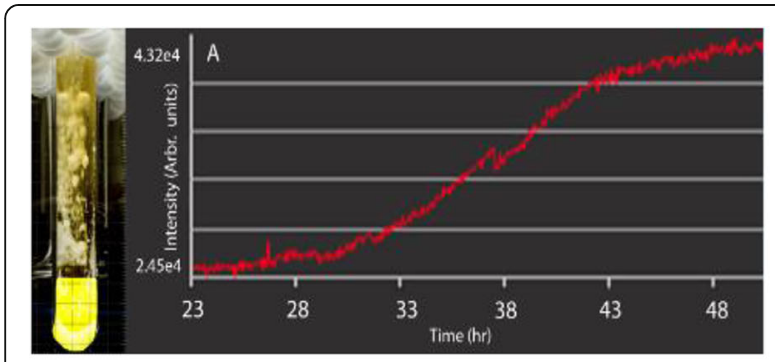

A

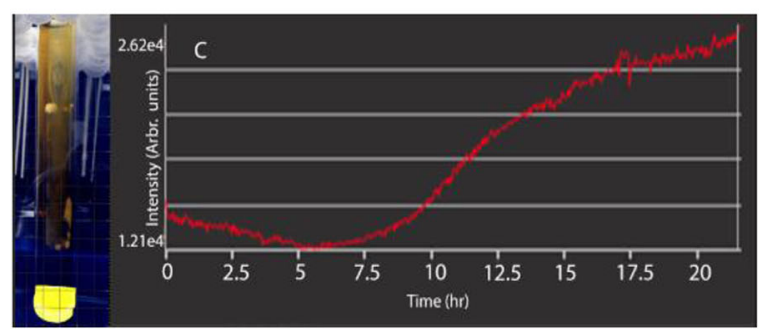

C

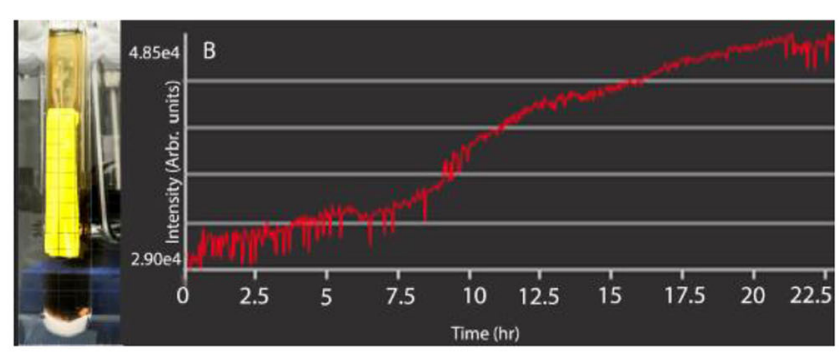

B

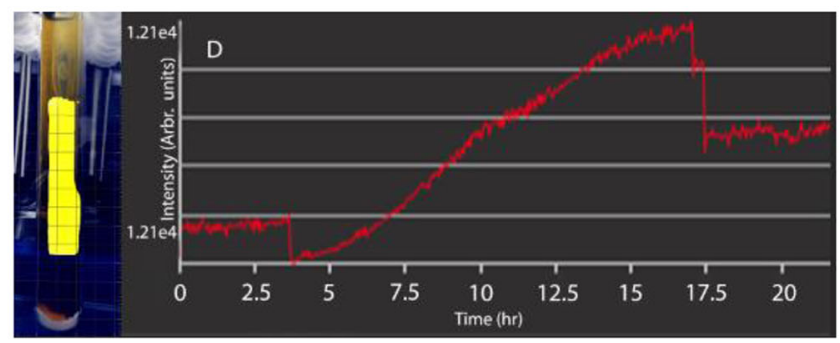

D

Fig. 1 a Biofilm development for second 24-h timeframe. Intensity reaches a steady increase as the biofilm detaches from the spatula and moves to the bottom of the microfermenter. $\mathbf{b}$ Growth of the attached phase: Quantification of biofilm dynamics for the first $24 \mathrm{~h}$ of development. Initial intensity measurements are due to background impedance for selected region of interest (attached phase) c Growth of the detached phase: Growth initiates at about $6 \mathrm{~h}$, and increases steadily due to spatula detachment, as well as growth from previous detachment. d Growth initiates at about $3.5 \mathrm{~h}$, and the biofilm grows until it hits the detachment phase, at roughly $16 \mathrm{~h}$. Once the detachment phase occurs there is a large drop off and then a constant plateau showing full biofilm maturation 


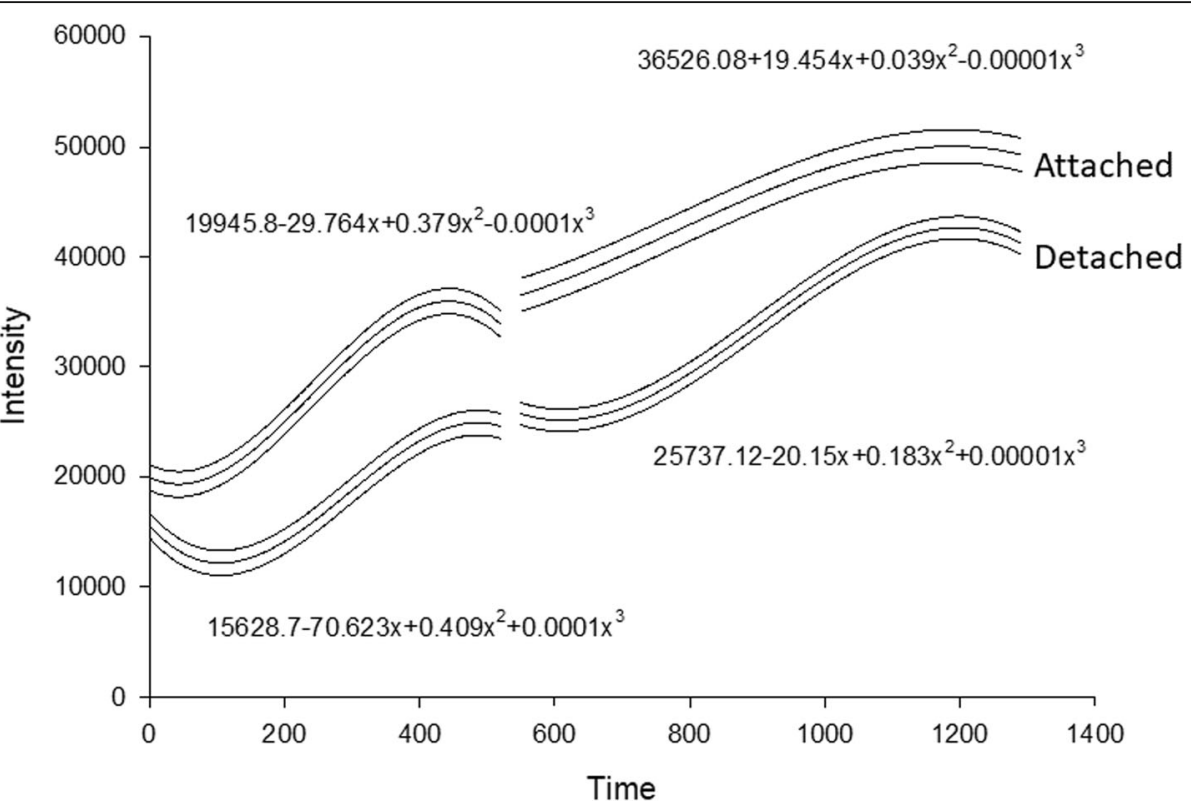

Fig. 2 Function of intensity on time in the biofilm growth in microfermenter. The left panel shows the cubic equations, the lines represent mean and $95 \%$ confident intervals for each condition attached and detached. Notice there is not overlap between functions. Notice there is not overlap between functions. Intensity is measured in arbitrary units, and time ( $\mathrm{x}$ - axis) correspond to the ranked samples for $48 \mathrm{~h}$

two phases at 24h. (Supplementary Table 2S) and 35 transcripts differ - at $48 \mathrm{~h}$. of growth in micro-fermenter (Supplementary Table 3S). The main pathways, that were down-regulated in the attached phase after $24 \mathrm{~h}$. in culture were transcriptional regulation, purine nucleotide biosynthesis, and L-aspartate biosynthesis, the upregulated pathways were fatty acid and phospholipid metabolism, ABC transporters (maltooligosaccharide, glutamine and oligopeptide transport systems) (Supplementary Fig. 3S), and purine nucleotide biosynthesis (Supplementary Fig. 4S). The Principal component analyses (PCA) demonstrated distinguishable differences between attached and detached phases after $24 \mathrm{~h}$ of biofilm growth (Fig. 3).

From 35 differently regulated transcripts at $48 \mathrm{~h}$ in culture, 33 molecules were down-regulated in A, compared to $\mathrm{D}$ phases, the main pathways affected were transcriptional regulation, fermentation and pyrimidine nucleotide biosynthesis. The comparison in gene expression in A phase of biofilm location revealed, that 29 genes were down-regulated and 2 genes were upregulated at $48 \mathrm{~h}$.' compared to 24 h.' time-point. From the 29 down-

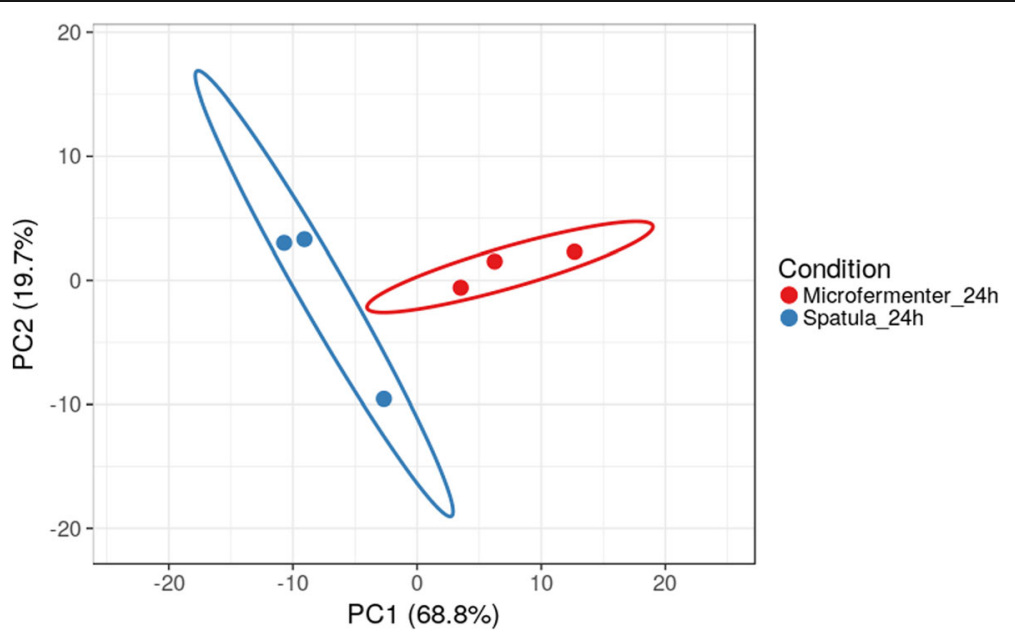

Fig. 3 Principal component analyses of genes, expressed in biofilms, grown under different conditions (attached - spatula and detached (dispersed, microfermenter)) 
regulated genes, 14 genes belonged to the purine synthesis pathway.

\section{Electrical impedance curves of different bacterial strains} The growth of $L B$ resulted in an initial decrease in CI, which was $L B$ species-specific in amplitude and duration. This decrease was followed by an increase and subsequent growth plateau (Fig. 4, Table 1).

The presence of diluted $L$. jensenii delayed the growth of $L$. gasseri. This inhibitory property of $L$. jensenii was demonstrated across a broad range of $L$. gasseri concentrations (Fig. 5).

\section{Discussion}

L. plantarum is associated with oral and gut microbiomes and plays an important role in lipid metabolism [26], regulation of host growth [27], gut permeability [28], and antimicrobial defenses [29, 30]. L. plantarum has strong adhesive properties [23] and has been used as a probiotic for treatment of different conditions [31, 32] [33]. Time-curves of growth and maturation of L. plantarum were similar in both systems (microfermenter and XCELLigence); however, the detachment phase was not detectable in the impedance-based system in our study. This could be attributed to the differences between these two systems: the biomass, accumulated in microfermenter is much higher than what can be reached in the XCELLigencee. Additionally the microfermenter has a continuous flow, such that no medium exhaustion is taking place, as it might be the case in the different system. This allows formation of very mature biofilm, which could be thus detached. The micro-fermenter therefore might better reflect the real situation of biofilm formation in vivo with fluxes of liquid that are imposed in these natural environments with rarely some nutrients exhaustion rarely occurring. The detachment and dissemination took place at approximately $17 \mathrm{~h}$. after initiation of the growth in the present study. Indeed, this time-frame is in line with the time of gastric emptying in humans [34]. The regulatory genes involved in the biofilm formation differ from those expressed in planktonic bacteria [5] and gene expression changes in bacterial biofilm over time [35]. Previous study of L. plantarum found several global regulators of gene expression, such as CtsR, HrcA, and CcpA, which upregulate the expression of various gene networks in response to stressors such as acidic or alkaline environments, high temperatures, and caloric restriction [36, 37]. These studies have indicated that, in response to stressors, $L$. plantarum changes its energy metabolism as well as its production of fatty acids and exopolysaccharides incorporated into biofilms [38, 39]. Our data agrees with these observations, demonstrating changes in oligosaccharide and fatty acid transports between attached (original place of biofilm formation) and detached phases after $24 \mathrm{~h}$. in flow culture. Polysaccharides are critical for biofilm formation, comprising structures and supporting biofilm growth [5]. Additional factors, contributing to differences between attached and detached biofilm portions could be attributed to different fluid flow rates around the spatula and at the bottom of microfermenter [40] and differences in spatial morphology of biofilm [41]. Interestingly, previous work has shown that under severe stresses $L$. plantarum induces expression of error-prone

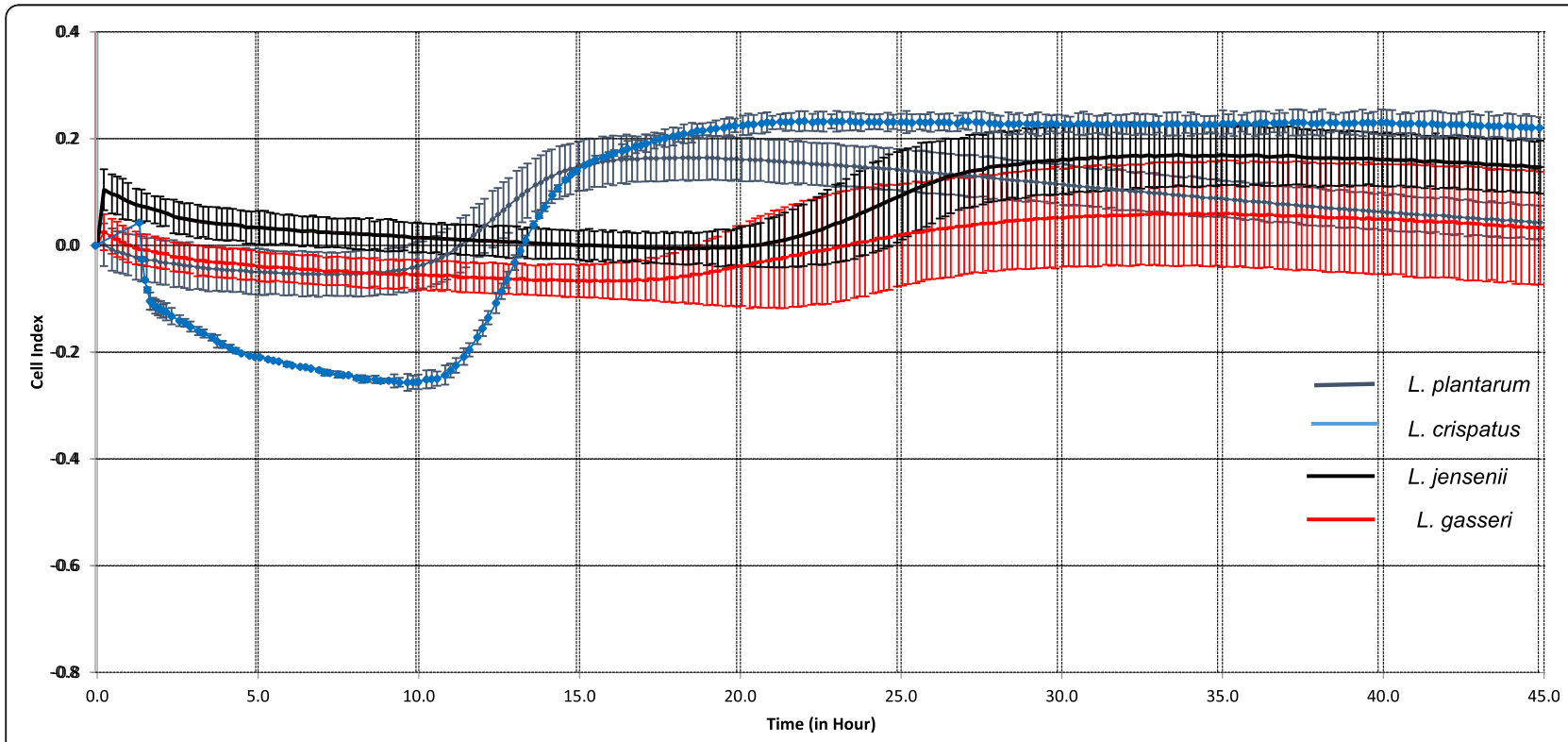

Fig. 4 Biofilm growth curves of L. plantarum, L. crispatus, L. gasseri and L. jensenii, as changes of the Cell Index over time, detected with XCELLIgence Real Time Cell Analyses Instrument (ACEA Bioscience Inc., San Diego, CA) 
Table 1 Duration of attachment, growth and biofilm maturation and cell index of four Lactobacilli species (L. plantarum, L. crispatus, L. jensenii and L.gasserii), detected, using X-Celligence methodology

\begin{tabular}{|c|c|c|c|c|c|}
\hline \multirow[t]{2}{*}{ Lactobacilli species } & \multicolumn{2}{|l|}{ Duration (h) } & \multicolumn{3}{|l|}{ Cell Index } \\
\hline & Attachment & Growth & Attachment & Growth slope & Maturation \\
\hline L. plantarum & 5.15 & 13.52 & -0.3172 & 0.00745 & 0.717 \\
\hline L. crispatus & 9.44 & 9.67 & --0.26 & 0.0109 & 0.25 \\
\hline L. jensenii & 19.52 & 13.95 & -0.0261 & 0.00815 & 0.11 \\
\hline L. gasserii & 12.22 & 12.27 & -0.1224 & 0.0082 & 0.25 \\
\hline
\end{tabular}

DNA polymerases and may undergo "genetic shuffling" $[42,43]$. Decrease in purine nucleotide synthesis in attached phase at $48 \mathrm{~h}$. compared to $24 \mathrm{~h}$. is in line with the time-line of biofilm formation, described in this study. Purine synthesis might be involved in regulation of L. plant biofilm growth in the similar manner as it has been described in other bacterial species. For example, in Pseudomonas aeruginosa mutation in purine synthesis gene slowed biofilm formation [44]. All of these mechanisms work synergistically to change gene expression to promote adaptation and survival, particularly to increase aggregation and adherence to surfaces, as well as metabolic change required for biofilm growth.

In general, the phases of the $L B$ biofilm development detected in the ex vivo experiments should be taken in consideration for in vivo biofilm and probiotic application. Healthy vaginal microbiota includes different ratios of L. crispatus, L. gasseri, L. jensenii [45]. Using conventional methods, differences in biofilm formation by different $L B$ strains were previously reported (e. g. crystal violet) [46]. These strain-specific $L B$ biofilm dynamics might be related to the bacterial surface-specific properties encoded by each genome [47]. Remarkably, the duration of attachment phases differed between different $L B$ while growth phases were quite similar. L. jensenii demonstrated the longest attachment phase and lower $\mathrm{CI}$, these properties could be associated with the lower protective properties of this $L B$, which in turn might be associated with the dominance of $L$. jensenii in vaginal milieu of abnormal pregnancies (e.g. preterm birth) [48]. The inhibitory effect of L. jensenii on the growth of L. gasseri found in this study is in line with this clinical observation and the fact that the dominance of $L$. gasseri is associated with the decreased risk of preterm birth [49]. The biofilm interaction between $L B$ species might represent the mechanisms of differential $L B$

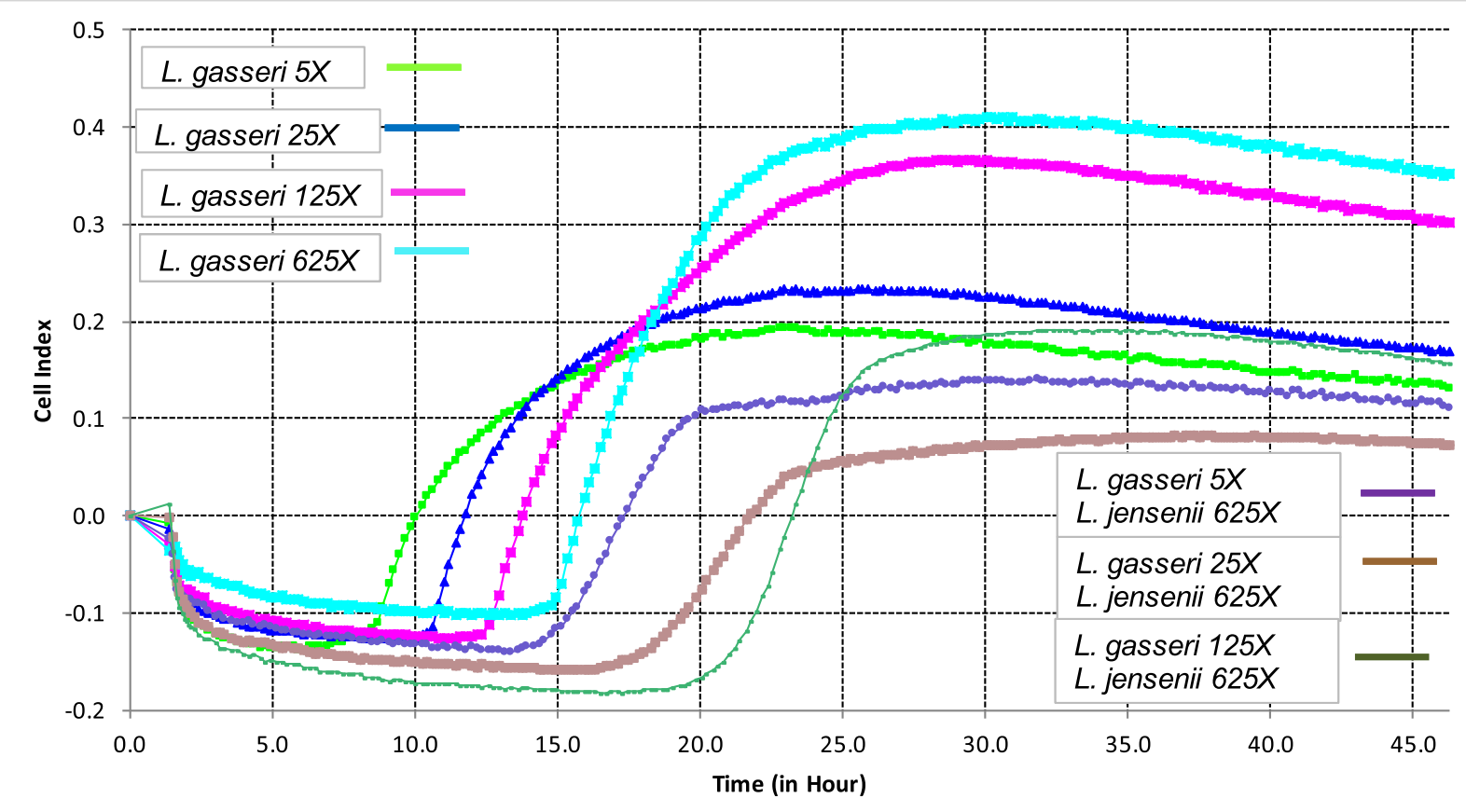

Fig. 5 Biofilm growth curves of Lactobacilli gasseri in presence of Lactobacilli jensenii biofilm, X-CELLIgence Real Time Cell Analyses Instrument (ACEA Bioscience Inc., San Diego, CA) 
expression in Verheist criteria-determined vaginal milieu [50].

According to Martin et al., L. jensenii strains adhered strongly to a plastic substrate [51]. The shortest attachment period and highest absolute $C I$ among vaginal $L B$ was detected in L. crispatus. This result is in line with strong adhesive force reported for this species [46]. The differences in the phenotypic surface properties of three $L B$ strains have been described by others [47], and agree with the findings noted in this study. Changes in the electrical impedance signal are bacterial species specific [52], thus this method could be used for development of the rapid diagnostic tool for bacterial detection of specific $L B$ composition.

\section{Conclusions}

The impedance-based technology could be used as a rapid screening tool for evaluation of competitive biofilm formation by different $L B$ in co-cultures, and the microfermenter system could be used as a subsequent step for biofilm growth by specific strains and subsequent therapeutic applications, which are based on the general fact that Lactobacilli stimulate and support a dynamic and healthy gut and vaginal milieu by protecting against pathogens [36].

\section{Method}

\section{Micro-fermenter}

L. plantarum (subsp. plantarum (ATCC ${ }^{\bullet} 14917^{m}$ )) was inoculated in a MRS (De Mann, Rogosa, and Sharpe) agar plate, which was subsequently incubated at $37^{\circ} \mathrm{C}$ for $24 \mathrm{~h}$. with $5 \% \mathrm{CO}_{2}$. The culture was then scraped into $6 \mathrm{ml}$ of an MRS broth. The Optical Density (OD) of the cell suspension was estimated using an EL 808 plate reader at $630 \mathrm{~nm}$ (Biotek, Winooske, Vermont, USA). A 1:10 OD dilution was made into a $50 \mathrm{ml}$ culture that was then used to inoculate a spatula in the micro-fermenter. The spatula remained submerged in the culture broth for 30 mins and was then placed in the micro fermenter tube. The tube was, in turn, was in turn submerged in a $37^{\circ} \mathrm{C}$ heating water bath in the continuous-flow culture system for either $24(n=6)$ or $48 \mathrm{~h}$. $(n=6)$. A peristaltic pump (Multichannel cassette pump, Watson-Marlow Inc., Wilmington, MA, USA) was utilized at $10 \mathrm{rpm}$ to push fresh MRS broth media through the system, which was pressurized with a mixture of $95 \% \mathrm{O}_{2}$ and $5 \% \mathrm{CO}_{2}$ (0.4 bar).

After 24 and $48 \mathrm{~h}$. the biofilm was then collected and stored for further analysis at $-80^{\circ} \mathrm{C}$. The purity of the culture was confirmed by Polymerase Chain Reaction (PCR), using Fast Start Essential DNA Green Master Mix (Roche, USA) with specific primer sets (Supplementary Table 1S), using Roche Light Cycler 96 (Applied Biosystems/Roche, USA).

\section{Video recording}

Real-time capture of the biofilm growth $(n=6$ : for full $48 \mathrm{~h}(n=4)$ and for $24 \mathrm{~h}$ ' time-frames $(n=2))$ was obtained using a Nikon D3200 (Nikon Inc. Melville, N. Y, U.S.A) digital camera. The photo-camera was placed externally in front of the micro-fermenter system. An external auto-timer shutter release (Shenzhen Pangshi technology, Ltd., Longhua Shenzhen, China) was set on a continuous cycle for image capture at a frequency of one frame every $2.5 \mathrm{~min}$. Images taken made during these time-points were organized, edited, and exported using Adobe Photoshop Lightroom (Adobe Systems Incorporated, San Jose, CA). Each time-point was then put together with Adobe Premiere Pro (Adobe Systems Incorporated, San Jose, CA) to create a full video clip of the dynamic stages of the biofilm development. The video was then transferred to the IMARIS software for further quantification.

\section{Quantification of the time-lapse video-recording of biofilm growth, using IMARIS system}

Analyses of the biofilm growth from video recordings ( $n=5$, for 24 and 48 , attached and detached phases) were performed using an algorithm developed by IMARIS Microscopy Image analyses software (Bitplane, Oxford Instrument Company, Concord, MA, USA). Regions of interest were selected for both the spatula (attached phase, A) and the bottom of the microfermenter (detached phase, D) for data collection and quantification. This also allowed the software to focus only on intensity changes within the given parameters and region. The initial intensity reading was performed at timepoint 0 and defined as a "background noise." Corrections were also made for the heating coil and bubbles attached to the glassware, which were picked up by IMARIS as biofilm intensity in the selected region of interest.

\section{Mathematical modelling}

The intensity as a function of time demonstrated a sigmoidal shape. We calculated the beta value (slope) on the linear part of the curve. Four mathematical models were tested for goodness of fit of the function intensity on time. The evaluated models were liner, quadratic, cubic and exponent. These models were analyzed during the first $24 \mathrm{~h}$ and in a second model (a third was with intercept adjustment at basal) after $24 \mathrm{~h}$ of $48 \mathrm{~h}$ of growth. The SPSS v26 software was used for the analysis.

\section{RNA extraction and sequencing}

Biofilm was collected separately from A and D phases after 24 ( $n=3$ each) and $48 \mathrm{~h}$. ( $n=3$ each) of culture flash frozen in liquid nitrogen and stored at $-80^{\circ} \mathrm{C}$ for future analyses. RNA was extracted, using TRIzol ${ }^{\mathrm{Tm}}$ 
reagent [37] and Next Generation sequencing (NGS) was performed as previously described [38], utilizing the Illumina MiSeq platform (San Diego, CA). We compared whole genome expression of biofilms from the A and D phases at the bottom of the fermenter as validation of biofilm formation/maturation capacities as well as of biofilm growth by measuring both bacterial biomass from the spatula and from the bottom of the microfermenter in a time-dependent manner ( 24 and $48 \mathrm{~h}$.).

\section{Analysis of the RNA-seq data}

Rockhopper 2.03 software (https://cs.wellesley.edu/ btjaden/Rockhopper/) [39] was used to analyze RNA-seq data, implementing reference-based transcript alignment to Lactobacillus plantarum subsp. plantarum ATCC 14917 as a reference genome. Total transcriptomes were normalized by upper quartile normalization, then transcript abundance was quantified using reads assigned per kilobase of target per million mapped reads (RPKM). Differential gene expression was measured using local regression with an error term modelled with a negative binomial distribution. The Benjamini-Hochberg procedure [53] was used to correct for multiple testing and $q$ values were reported, which reflect adjusted $p$-values. Selection criteria for differential expression for genes included a fold change greater than 2 and a $q$-value less than 0.05. Kyoto Encyclopedia of Genes and Genome database (KEGG; https://www.genome.jp/kegg/) [42, 43] was used to map the identified genes to available and annotated pathways of Lactobacillus plantarum genome.

\section{XCELLigence assays}

The xCELLigence (ACEA Bioscience Inc., San Diego, CA) system is based on impedance measurement of the cells, seeded on the 16 well plate with gold biosensors [54].

The strains Lactobacillus_gasseri_CIP102991T, Lactobacillus_jensenii_CIP69.17 T and Lactobacillus_crispatus_CIP103603 were obtained from the Institute Pasteur strains collection (CIP). Prior to the experiments, strains of $L$. plantarum, L. jensenii, L. crispatus and L. gasseri were inoculated and overnight bacterial culture was grown at $37^{\circ} \mathrm{C}\left(5 \% \mathrm{CO}_{2}, 95 \% \mathrm{O}_{2}\right)$. The OD of the cell suspension was estimated using an EL 808 plate reader (Biotek, Winooske, Vermont, USA). The density of the seeding was estimated during preliminary experiments (Supplementary material, Fig. 2S). Each well of the xCELLigence E-Plate 16 PET (ref \# 00300600890 from ACEA Biosciences, Inc., San Diego, CA, USA) was filled with $100 \mu \mathrm{l}$ media and cells were seeded at the optimal density. Additionally, L. jensenii and L. gasseri were seeded in the same wells to evaluate competition between these $L B$ subspecies during biofilm formation (one run, $n=2$ ). Since each bacterial biofilm had a specific impedance curve, bacterial identification was performed based on the curve analyses. The impedance was registered as a Cell Index (CI), which was detected by the gold electrodes, placed on the bottom of the 16well plate. The instrument measures the strength of attachment of the biofilm layer and the relative impedance is recorded in user-defined intervals continually in real time from the incubator.

The set up allowed simultaneous experiments in three 16 well plates. Each experiment was performed twice and in duplicate for each run. The principles of the assay are described elsewhere [54]. The growth slope (for attachment and proliferation phases) and Maximal CI (for mature biofilm) have been measured.

\section{Supplementary information}

Supplementary information accompanies this paper at https://doi.org/10. 1186/s12866-020-01753-3.

Additional file 1 Table 1S. Primers' set used for the conformation of $L$. plantarum biofilm purity.

Additional file $\mathbf{2}$ Table $\mathbf{2 S}$. Comparison of whole genome expression between attached and detached phases of biofilm growth of $L$. plantarum at $24 \mathrm{~h}$.

Additional file $\mathbf{3}$ Table $\mathbf{3 S}$. Comparison of whole genome expression between attached and detached phases of biofilm growth of $L$. plantarum at $48 \mathrm{~h}$. and 35 transcripts differ - at $48 \mathrm{~h}$. of growth in microfermenter (Supplementary Table 2).

Additional file 4 Figure 1S. Representation amplification curves (A) and melting picks (B) of PCR amplification products of $L$. plantarum (housekeeping gene and eubacteria specific primers) used for conformation of biofilm purity.

Additional file $\mathbf{5}$ Figure $\mathbf{2 S}$. Electrical impedance signaling expressed as cell index, registered using XCELLigence assays of $L$. plantarum biofilm growth at the initial dilutions $5 x, 25 x, 125 x$ and $625 x$ of overnight bacterial culture. The most robust signal was obtained by seeding the lowest number of cells (i.e. the $625 x$ dilution is the best, while the $5 x$ dilution is the worst).

Additional file 6 Figure 3S. The upregulated $A B C$ transporters pathway (maltooligosaccharide, glutamine and oligopeptide transport systems) in attached compared to the detached phases of biofilm growth after $24 \mathrm{~h}$.

Additional file $\mathbf{7}$ Figure $\mathbf{4 S}$. The upregulated purine nucleotide biosynthesis pathway in attached compared to the detached phases of biofilm growth after $24 \mathrm{~h}$.

Additional file 8 Video-recording $\mathbf{S}$. Video-recording of L. plantarum biofilm growth in microfermenter system during $48 \mathrm{~h}$.

\section{Abbreviations \\ A: Attached phase, growth on the spatula in microfermenter system; Cl: Cell index; D: Detached phase, growth on the bottom of the microfermenter; LB: Lactobacilli species; Spp: Species}

\section{Acknowledgements}

Authors are thankful to Drs. Christophe Beloin and Jean-Marc Ghigo (Groupe de Génétique des Biofilms, Institut Pasteur, France) for transmission of the microfermenter technology. We acknowledge help of Dr. Amanda Howard, Regional Sales Engineer of Bitplane (Oxford Instrument Company, Concord, MA, USA). Critical advices and expertise of Mr. Brandon Lamarche (ACEA Biosciences, Inc., San Diego, CA, USA) is very much appreciated. Help from Mr. Elihu Arzate (TTUHSC, USA) was instrumental for the development of videorecording of biofilm growth. We also acknowledge Mr. Brance Davis for his work as editor, the resources of Center for Biotechnology TTU, and the expert advice of Dr. Rao Kottapalli. Authors acknowledge expert help of Juan- 
Carlos Lopez-Alvarenga MD, PhD (University of Texas at Rio-Grande Valley, TX) with mathematical modelling.

\section{Authors' contributions}

SM, JGG, RW, AW, and DH performed experiments. SM, JGG, RW, ME, AW, AH, $\mathrm{DH}$, and NSL analyzed data. BG, GV, and NSL interpreted data. SM, JGG, RW, $M E, A W, A H, D H, B G$, and NSL contributed to manuscript writing. All have approved the submitted version.

\section{Funding}

There are no sources of funding to declare.

\section{Availability of data and materials}

All data generated or analyzed during this study are included in this published article [and its supplementary information files].

\section{Ethics approval and consent to participate}

Not applicable.

\section{Consent for publication}

Not applicable.

\section{Competing interests}

The authors declare that they have no competing interests.

\section{Author details}

${ }^{1}$ Texas Tech University Health Sciences Center at the Permian Basin, 701 W. 5th Street, Odessa, TX 79763, USA. ${ }^{2}$ University of Texas at the Permian Basin Odessa, TX, USA. ${ }^{3}$ Department of Biological Sciences, Texas Tech University, Lubbock, TX, USA. ${ }^{4}$ Department of Microbiology and Immunology, Texas Tech University Health Sciences Center, Lubbock, TX, USA. ${ }^{5}$ ACEA Biosciences, Inc., San Diego, CA, USA. ${ }^{6}$ Department of Neurobiology and Pharmacology, Texas Tech University Health Sciences Center, Lubbock, TX, USA.

Received: 4 March 2019 Accepted: 13 March 2020

Published online: 24 March 2020

\section{References}

1. Beitelshees M, Hill A, Jones CH, Pfeifer BA. Phenotypic Variation during Biofilm Formation: Implications for Anti-Biofilm Therapeutic Design. Materials (Basel, Switzerland). 2018;11(7).

2. Kinross JM, Darzi AW, Nicholson JK. Gut microbiome-host interactions in health and disease. Genome Med. 2011:3(3):14.

3. Xiao J, Chen L, Johnson S, Yu Y, Zhang X, Chen J. Predictive modeling of microbiome data using a phylogeny-regularized generalized linear mixed model. Front Microbiol. 2018;9:1391.

4. Ribet D, Cossart P. How bacterial pathogens colonize their hosts and invade deeper tissues. Microbes Infect. 2015;17(3):173-83.

5. Beloin C, Ghigo JM. Finding gene-expression patterns in bacterial biofilms. Trends Microbiol. 2005;13(1):16-9.

6. Haney EF, Trimble MJ, Cheng JT, Valle Q, REW H. Critical Assessment of Methods to Quantify Biofilm Growth and Evaluate Antibiofilm Activity of Host Defence Peptides. Biomolecules. 2018;8(2).

7. Sauer MM, Jakob RP, Eras J, Baday S, Eris D, Navarra G, Berneche S, Ernst B, Maier T, Glockshuber R. Catch-bond mechanism of the bacterial adhesin FimH. Nat Commun. 2016;7:10738.

8. Kline KA, Falker S, Dahlberg S, Normark S, Henriques-Normark B. Bacterial adhesins in host-microbe interactions. Cell Host Microbe. 2009:5(6):580-92.

9. Tshikantwa TS, Ullah MW, He F, Yang G. Current trends and potential applications of microbial interactions for human welfare. Front Microbiol. 2018;9:1156

10. Bezek K, Kurincic M, Knauder E, Klancnik A, Raspor P, Bucar F, Smole Mozina S. Attenuation of adhesion, biofilm formation and quorum sensing of campylobacter jejuni by Euodia ruticarpa. Phytotherapy Res : PTR. 2016; 30(9):1527-32

11. Caufield PW, Schon CN, Saraithong P, Li Y, Argimon S. Oral Lactobacilli and Dental Caries: A Model for Niche Adaptation in Humans. J Dent Res. 2015; 94(9 Suppl):110s-8s.

12. Milani C, Duranti S, Mangifesta M, Lugli GA, Turroni F, Mancabelli L, Viappiani A, Anzalone R, Alessandri G, Ossiprandi MC, et al. Phylotype-level profiling of lactobacilli in highly complex environments by means of an internal transcribed spacer-based metagenomic approach. Appl Environ Microbiol. 2018:84(14).

13. Pothuraju R, Sharma RK. Interplay of gut microbiota, probiotics in obesity: a review. Endocr Metab Immune Disord Drug Targets. 2018;18(3):212-20.

14. Heeney DD, Gareau MG, Marco ML. Intestinal Lactobacillus in health and disease, a driver or just along for the ride? Curr Opin Biotechnol. 2018;49: $140-7$.

15. Amabebe $\mathrm{E}$, Anumba DOC. The vaginal microenvironment: the physiologic role of lactobacilli. Front Med. 2018;5:181.

16. Valenti P, Rosa L, Capobianco D, Lepanto MS, Schiavi E, Cutone A, Paesano $R$, Mastromarino P. Role of lactobacilli and Lactoferrin in the mucosal Cervicovaginal defense. Front Immunol. 2018:9:376.

17. Soto A, Martin V, Jimenez E, Mader I, Rodriguez JM, Fernandez L. Lactobacilli and bifidobacteria in human breast milk: influence of antibiotherapy and other host and clinical factors. J Pediatr Gastroenterol Nutr. 2014;59(1):7888.

18. Phukan N, Brooks AES, Simoes-Barbosa A. A cell surface aggregationpromoting factor from Lactobacillus gasseri contributes towards inhibition of Trichomonas vaginalis adhesion to human vaginal ectocervical cells. Infect Immun. 2018;86(8)

19. Kaur S, Sharma P, Kalia N, Singh J, Kaur S. Anti-biofilm properties of the fecal probiotic lactobacilli against Vibrio spp. Front Cell Infect Microbiol. 2018;8: 120.

20. Ding YH, Qian LY, Pang J, Lin JY, Xu Q, Wang LH, Huang DS, Zou H. The regulation of immune cells by lactobacilli: a potential therapeutic target for anti-atherosclerosis therapy. Oncotarget. 2017;8(35):59915-28.

21. Dellias MTF, Borges CD, Lopes ML, da Cruz SH, de Amorim HV, Tsai SM. Biofilm formation and antimicrobial sensitivity of lactobacilli contaminants from sugarcane-based fuel ethanol fermentation. Antonie van Leeuwenhoek. 2018;111(9):1631-44.

22. Kubota $H$, Senda $\mathrm{S}$, Nomura $N$, Tokuda H, Uchiyama H. Biofilm formation by lactic acid bacteria and resistance to environmental stress. J Biosci Bioeng. 2008;106(4):381-6.

23. Wen ZT, Liao S, Bitoun JP, De A, Jorgensen A, Feng S, Xu X, Chain PSG, Caufield PW, Koo H, et al. Streptococcus mutans displays altered stress responses while enhancing biofilm formation by Lactobacillus casei in mixed-species consortium. Front Cell Infect Microbiol. 2017:7:524.

24. Slizova M, Nemcova R, Mad'ar M, Hadryova J, Gancarcikova S, Popper M, Pistl J. Analysis of biofilm formation by intestinal lactobacilli. Can J Microbiol. 2015;61(6):437-46.

25. Terraf MC, Juarez Tomas MS, Nader-Macias ME, Silva C. Screening of biofilm formation by beneficial vaginal lactobacilli and influence of culture media components. J Appl Microbiol. 2012;113(6):1517-29.

26. Korpela K, Mutanen A, Salonen A, Savilahti E, de Vos WM, Pakarinen MP. Intestinal microbiota signatures associated with histological liver Steatosis in pediatric-onset intestinal failure. JPEN J Parenter Enteral Nutr. 2017:41(2): $238-48$

27. Schwarzer M, Makki K, Storelli G, Machuca-Gayet I, Srutkova D, Hermanova P, Martino ME, Balmand S, Hudcovic T, Heddi A, et al. Lactobacillus plantarum strain maintains growth of infant mice during chronic undernutrition. Science (New York, NY). 2016;351(6275):854-7.

28. Shukla PK, Meena AS, Manda B, Gomes-Solecki M, Dietrich P, Dragatsis I, Rao R. Lactobacillus plantarum prevents and mitigates alcohol-induced disruption of colonic epithelial tight junctions, endotoxemia, and liver damage by an EGF receptor-dependent mechanism. FASEB J. 2018: fj201800351R

29. Lin TH, Pan TM. Characterization of an antimicrobial substance produced by Lactobacillus plantarum NTU 102. J Microb, Immunol Infect. 2019:52(3):409-17.

30. Tsai CC, Hung YH, Chou LC. Evaluation of lactic acid bacteria on the inhibition of Vibrio parahaemolyticus infection and its application to food systems. Molecules (Basel, Switzerland). 2018;23(5).

31. Satish L, Gallo PH, Johnson S, Yates CC, Kathju S. Local probiotic therapy with Lactobacillus plantarum mitigates scar formation in rabbits after burn injury and infection. Surg Infect. 2017;18(2):119-27.

32. Lukic J, Chen V, Strahinic I, Begovic J, Lev-Tov H, Davis SC, Tomic-Canic M, Pastar I. Probiotics or pro-healers: the role of beneficial bacteria in tissue repair. Wound Repair Regen. 2017:25(6):912-22.

33. Kim S, Huang E, Park S, Holzapfel W, Lim SD. Physiological characteristics and anti-obesity effect of Lactobacillus plantarum K10. Korean J Food Sci Anim Resour. 2018;38(3):554-69. 
34. Lee YY, Erdogan A, Rao SS. How to assess regional and whole gut transit time with wireless motility capsule. J Neurogastroenterol Motil. 2014;20(2): 265-70

35. Sauer K, Camper AK. Characterization of phenotypic changes in Pseudomonas putida in response to surface-associated growth. J Bacteriol. 2001;183(22):6579-89.

36. Ventolini G. Vaginal Lactobacillus: biofilm formation in vivo - clinical implications. Int J Women's Health. 2015;7:243-7.

37. Atshan SS, Shamsudin MN, Karunanidhi A, van Belkum A, Lung LT, Sekawi Z, Nathan JJ, Ling KH, Seng JS, Ali AM, et al. Quantitative PCR analysis of genes expressed during biofilm development of methicillin resistant Staphylococcus aureus (MRSA). Infect Genet Evol. 2013;18:106-12.

38. Kruczek C, Kottapalli KR, Dissanaike S, Dzvova N, Griswold JA, ColmerHamood JA, Hamood AN. Major Transcriptome changes accompany the growth of Pseudomonas aeruginosa in blood from patients with severe thermal injuries. PLoS One. 2016;11(3):e0149229.

39. McClure R, Balasubramanian D, Sun Y, Bobrovskyy M, Sumby P, Genco CA, Vanderpool CK, Tjaden B. Computational analysis of bacterial RNA-Seq data. Nucleic Acids Res. 2013;41(14):e140.

40. Thomen P, Robert J, Monmeyran A, Bitbol AF, Douarche C, Henry N. Bacterial biofilm under flow: first a physical struggle to stay, then a matter of breathing. PLoS One. 2017;12(4):e0175197.

41. Serra DO, Hengge R. Stress responses go three dimensional - the spatial order of physiological differentiation in bacterial macrocolony biofilms. Environ Microbiol. 2014;16(6):1455-71.

42. Kanehisa M, Furumichi M, Tanabe M, Sato Y, Morishima K. KEGG: new perspectives on genomes, pathways, diseases and drugs. Nucleic Acids Res. 2017:45(D1):D353-d361.

43. Kanehisa M, Sato Y, Kawashima M, Furumichi M, Tanabe M. KEGG as a reference resource for gene and protein annotation. Nucleic Acids Res. 2016;44(D1):D457-62.

44. Yoshioka S, Newell PD. Disruption of de novo purine biosynthesis in Pseudomonas fluorescens PfO-1 leads to reduced biofilm formation and a reduction in cell size of surface-attached but not planktonic cells. PeerJ. 2016;4:e1543.

45. Petrova Ml, Lievens E, Malik S, Imholz N, Lebeer S. Lactobacillus species as biomarkers and agents that can promote various aspects of vaginal health. Front Physiol. 2015;6:81.

46. Younes JA, van der Mei HC, van den Heuvel E, Busscher HJ, Reid G. Adhesion forces and coaggregation between vaginal staphylococci and lactobacilli. PLoS One. 2012;7(5):e36917.

47. Leccese Terraf MC, Mendoza LM, Juarez Tomas MS, Silva C, Nader-Macias ME. Phenotypic surface properties (aggregation, adhesion and biofilm formation) and presence of related genes in beneficial vaginal lactobacilli. J Appl Microbiol. 2014;117(6):1761-72.

48. Stafford GP, Parker JL, Amabebe E, Kistler J, Reynolds S, Stern V, Paley M, Anumba DOC. Spontaneous preterm birth is associated with differential expression of vaginal metabolites by lactobacilli-dominated microflora. Front Physiol. 2017:8:615

49. Tabatabaei N, Eren AM, Barreiro LB, Yotova V, Dumaine A, Allard C, Fraser WD. Vaginal microbiome in early pregnancy and subsequent risk of spontaneous preterm birth: a case-control study. BJOG. 2019;126(3):349-58

50. De Backer E, Verhelst $R$, Verstraelen $H$, Alqumber MA, Burton JP, Tagg JR, Temmerman M, Vaneechoutte M. Quantitative determination by real-time PCR of four vaginal Lactobacillus species, Gardnerella vaginalis and Atopobium vaginae indicates an inverse relationship between $L$ gasseri and L iners. BMC Microbiol. 2007:7:115.

51. Martin R, Soberon N, Vaneechoutte M, Florez AB, Vazquez F, Suarez JE. Characterization of indigenous vaginal lactobacilli from healthy women as probiotic candidates. Int Microbiol. 2008;11(4):261-6.

52. van Duuren J, Musken M, Karge B, Tomasch J, Wittmann C, Haussler S, Bronstrup M. Use of single-frequency impedance spectroscopy to characterize the growth dynamics of biofilm formation in Pseudomonas aeruginosa. Sci Rep. 2017;7(1):5223.

53. Benjamini $Y$, Hochberg $Y$. Controlling the false discovery rate: a practical and powerful approach to multiple testing. J R Stat Soc Ser B Methodol. 1995;57(1):289-300.

54. Gutierrez D, Hidalgo-Cantabrana C, Rodriquez A, Garcia P, Ruas-Madiedo P. Monitoring in real time the formation and removal of biofilms from clinical related pathogens using an impedance-based technology. PLoS One. 2016; 11(10):e0163966

\section{Publisher's Note}

Springer Nature remains neutral with regard to jurisdictional claims in published maps and institutional affiliations.

\section{Ready to submit your research? Choose BMC and benefit from:}

- fast, convenient online submission

- thorough peer review by experienced researchers in your field

- rapid publication on acceptance

- support for research data, including large and complex data types

- gold Open Access which fosters wider collaboration and increased citations

- maximum visibility for your research: over $100 \mathrm{M}$ website views per year

At $\mathrm{BMC}$, research is always in progress.

Learn more biomedcentral.com/submissions 